CARDIOVASCULAR MEDICINE

\title{
Circumstances of out of hospital cardiac arrest in patients with ischaemic heart disease
}

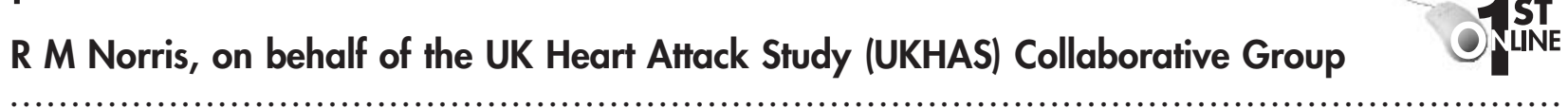

Heart 2005:91:1537-1540. doi: 10.1136/hrt.2004.057018

\begin{abstract}
Objectives: To discover the circumstances of out of hospital cardiac death irrespective of resuscitation attempts.

Design: Prospective community study over the two years 1994 and 1995.

Setting: The health districts of Brighton, South Glamorgan, and York, UK.

Subjects: 1290 victims of sudden death or cardiac arrest caused by coronary heart disease who were under 76 years of age.

Interventions: Basic and advanced life support for witnessed cardiac arrests.

Main outcome measures: Survival to reach hospital and for 30 days after the arrest.

Results: $35(35 \%)$ of 101 patients (mean age 64) whose arrest was witnessed by a doctor or paramedic survived for 30 days compared with 9 of $464(2 \%)$ whose arrest was witnessed by a relative or bystander at home (mean age 66) and 15 of $200(8 \%$ ) whose arrest was witnessed in a public place (mean age 61). None of the 525 victims of an unwitnessed arrest survived but the majority of those whose arrest was witnessed had complained of new symptoms before the arrest. Victims who were given basic life support by relatives or bystanders had better survival $(14$ of $183(8 \%))$ than those who were not (10 of $481(2 \%)$, $p<0.001$ ). Of the $20 \%$ of arrests that occurred in public places, few were in places where public access defibrillators would now be available.

Conclusions: The burden of out of hospital cardiac arrest is mainly in the home but most victims have premonitory symptoms. Public education to seek help urgently for new or prolonged chest pain seems the most promising method to address the problem.
\end{abstract}

Correspondence to: Dr Robin Norris, 17 Aberdeen Road, Castor Bay, Auckland, New Zealand; robinnorris@ orcon.net.nz

Accepted 20 April 2005 Published Online First 17 June 2005

$\mathrm{P}$ erhaps the most intractable medical problem of developed countries is out of hospital death from cardiac arrest, usually ventricular fibrillation, of people with coronary heart disease. Of the minority who are resuscitated from arrest, some develop a new myocardial infarct but many do not. ${ }^{1}$ Two thirds to three quarters of coronary heart attack deaths occur outside hospital, ${ }^{2}{ }^{3}$ and this proportion is even greater for younger than for older victims. ${ }^{3}$ Defibrillation by trained paramedics has had a modest effect in reducing the toll, and $30-40 \%$ of successful defibrillations in the UK are performed outside hospital by paramedics. ${ }^{3}$ When a defibrillator is not immediately available, bystander initiated cardiopulmonary resuscitation (CPR) before the arrival of paramedics increases survival rates further. ${ }^{5}$ Recently, to reduce delay to defibrillation for arrests occurring in public places, more than 700 automatic external defibrillators, which can be activated by lay witnesses of cardiac arrest, have been provided, mainly in airports and main line railway stations. ${ }^{67}$ The success of this latest initiative will depend on the proportion of arrests that occurs in such places and the presence of witnesses who either can use the devices or can summon someone who can.

The purpose of the present report is to re-examine the relation between site of arrest, presence of witnesses, lay attempts at resuscitation, and the use and success of subsequent advanced life support in preventing death from out of hospital arrest based on data from the UKHAS (UK heart attack study), ${ }^{3}$ which was performed during 1994-95, before public access defibrillators became available. Our study had the advantage over others ${ }^{8-11}$ that we recorded all cases of arrest and not just those in which resuscitation had been attempted.

\section{METHODS}

Methods of UKHAS have been published elsewhere. ${ }^{3} 12$ Briefly, we enlisted the help of general practitioners in the health districts of Brighton, South Glamorgan, and York (total population 954000 ) to provide us with details of all people up to 75 years of age who had died outside hospital of acute coronary heart attacks over two years (1994 and 1995). Case notes were retrieved from the Family Health Services Authority if necessary. Cases were identified in the first place from transcripts of death certificates provided to the health authorities by the Registrar of Deaths and were included only if ischaemic heart disease was shown as the principal cause of death at the coroner's necropsy ( $86 \%$ of cases) or, in the absence of necropsy, the patient had a history of ischaemic heart disease and died suddenly or after prolonged chest pain and had no other apparent cause of death. Patients who had survived out of hospital arrest were identified from the hospital records. Patients who died in chronic cardiac failure (as reported by the general practitioners) or had another terminal illness were excluded. Circumstances and treatment of arrests by ambulance personnel were obtained from the standard ambulance forms. Information on circumstances of death and reported premonitory symptoms was from coroners' officers as recorded on the necropsy reports or from the general practitioners. We recorded the place of arrest as the home, public place (street, workplace, mass gathering, or other public place), ambulance, general practitioner surgery, or nursing home. Witnesses were recorded as paramedical or medical staff, lay witnesses (relatives or bystanders), or no witness ("found dead"), and we noted whether bystander CPR had been attempted. The time of arrest, age of the victim, medical history, and reported symptoms before the arrest were also recorded. For unwitnessed arrests we recorded the time between the victim last

Abbreviations: CPR, cardiopulmonary resuscitation; MINAP, Myocardial Infarction National Audit Project; UKHAS, UK heart attack study 
being seen alive and the body being discovered Data were recorded on standardised forms and stored on computer at all three centres on a Paradox database (Corel, Maidenhead, UK). Significance of differences was assessed by use of the $\chi^{2}$ test.

At the time of our study one of the three centres had an active programme for citizen initiated CPR but, although all emergency ambulances carried defibrillators, no public access defibrillators were available. ${ }^{13}$

\section{RESULTS}

There were 1325 cases of out of hospital arrest, slightly more than those in previous reports, ${ }^{3}{ }^{12}$ which took the upper age as 74 rather than 75 years. There were no survivors from the 35 arrests that occurred in nursing homes, and this group is not considered further.

\section{Medically witnessed arrests}

Of the remaining 1290 cases, 43 patients had a cardiac arrest in an ambulance, of whom 27 (63\%) reached hospital alive and $16(37 \%)$ survived for 30 days. Among the nine patients who had an arrest in a doctor's surgery, three reached hospital alive and three (33\%) survived 30 days. These two groups accounted for $52(4 \%)$ of the 1290 out of hospital arrests. Of the remaining 1238 cases, 49 (4\%) were witnessed by a doctor or paramedic who had been called to the home or to the place where arrest subsequently occurred and of these patients 21 (43\%) reached hospital alive and $16(33 \%)$ survived for 30 days. In all, 35 of 101 (35\%) patients with a mean age of 64 years survived medically or paramedically witnessed arrests.

\section{Non-medically witnessed and unwitnessed arrests: effect of location}

Of 1189 arrests that were not medically witnessed, 957 (80\%) occurred in the home and $232(20 \%)$ in a public place (the street, 104; workplace, 23; mass gathering, 4; or other public place, usually a shop, restaurant or public house, sports venue, hotel, coach, or taxi, 101). We recorded no arrests in railway stations but one arrest occurred in a station restaurant.

Table 1 compares age and history of victims of arrest in the home versus a public place. Table 2 shows the proportion of arrests that were witnessed, together with the proportions receiving bystander initiated CPR and advanced life support from ambulance personnel, reaching hospital alive, and surviving for 30 days. Victims of arrest at home were five years older on average than those whose arrest occurred in a public place (table 1), but they had no greater co-morbidity

Table 1 Characteristics of victims of arrest at home versus in a public place

\begin{tabular}{|c|c|c|c|}
\hline & $\begin{array}{l}\text { Home } \\
(\mathrm{n}=957)^{*}\end{array}$ & $\begin{array}{l}\text { Public place } \\
\text { ( } \mathrm{n}=232 \text { ) }\end{array}$ & p Value \\
\hline \multicolumn{4}{|l|}{ Age (years) and sex } \\
\hline$<66$ & $372(39 \%)$ & $136(59 \%)$ & $<0.001$ \\
\hline $66-75$ & $578(61 \%)$ & $96(41 \%)$ & $<0.001$ \\
\hline Mean (SD) age & $66(8)$ & 61 (11) & $<0.001$ \\
\hline Men & $71 \%$ & $91 \%$ & $<0.001$ \\
\hline \multicolumn{4}{|l|}{ History† } \\
\hline $\mathrm{Ml}$ & $240(26 \%)$ & 75 (34\%) & $<0.05$ \\
\hline Cardiac failure & $159(17 \%)$ & $42(19 \%)$ & NS \\
\hline Stroke & $106(11 \%)$ & $16(7 \%)$ & NS \\
\hline$O A D$ & $129(14 \%)$ & $27(12 \%)$ & NS \\
\hline
\end{tabular}

*Details of seven victims unknown, none of whom survived; tknown in $94-98 \%$ of cases.

$\mathrm{MI}$, myocardial infarction; NS, not significant; $O A D$, obstructive airways disease. as shown by a history of myocardial infarction, heart failure, stroke, or obstructive airways disease. Surprisingly, a history of infarction was more common in people having an arrest in a public place than at home $(34 \% \vee 26 \%, \mathrm{p}<0.05)$.

Nearly $90 \%$ of arrests in a public place were witnessed compared with under $50 \%$ of those at home (table 2). Attempts at resuscitation by relatives or bystanders when arrest was witnessed were nearly twice as likely (41\% v 22\%) and survival was consequently four times as likely ( $8 \% v 2 \%)$ when the arrest occurred outside the home as when it occurred inside. No person whose arrest was not witnessed survived. For unwitnessed home arrests the median time between the victim last being seen alive and the body being discovered was nine hours.

\section{Arrest rhythm}

In all, 59 patients survived out of hospital arrest, 35 of whose arrests had been witnessed by a doctor or paramedic. The arrest rhythm was not recorded in most cases in which resuscitation by ambulance personnel had been unsuccessful, but was ventricular fibrillation or pulseless ventricular tachycardia in 51 of the 59 survivors, asystole or complete heart block in four, and not recorded in four.

\section{Effect of bystander CPR}

Of the 664 arrests in all locations that were witnessed by a non-medical person, 14 victims of $183(8 \%)$ who received bystander CPR survived compared with 10 of 481 (2\%) who did not $(\mathrm{p}<0.001)$

\section{Effect of age}

Considering all arrests witnessed by a non-medical person, survival of victims under 66 years of age ( 17 of $321(5 \%)$ ) was better than of those aged $>66$ (seven of $343(2 \%), p<0.05)$.

\section{Symptoms preceding arrest}

The presence or absence of symptoms preceding arrest was unknown in most of those whose arrest was unwitnessed or occurred outside the home. For the 464 victims of arrest in the home whose arrest was witnessed (by a relative in 398 of $464(86 \%))$, we were able to discover whether $369(80 \%)$ had complained of new symptoms. Of these, 264 (72\%) had reported symptoms, the principal symptoms being chest pain (145), breathlessness (47), or other symptoms, usually "feeling unwell" (72). In $184(70 \%)$ of the 264 patients, symptoms were reported to have lasted for longer than about 15 minutes.

\section{DISCUSSION}

Our study has the advantage that it includes all out of hospital cardiac arrests caused by coronary heart disease in the age group studied over a period of nearly two million person years of observation, with necropsy verification in $86 \%$ of those who died. Our study needs to be distinguished from

Table 2 Proportions of patients whose arrest was witnessed by a non-medical person and their subsequent fate

\begin{tabular}{llll}
\hline & $\begin{array}{l}\text { Home } \\
(\mathbf{n = 9 5 0 )}\end{array}$ & $\begin{array}{l}\text { Public place } \\
(\mathbf{n = 2 3 2 )}\end{array}$ & p Value \\
\hline Arrest witnessed & $464(49 \%)$ & $200(86 \%)$ & $<0.001$ \\
Bystander CPR & $101(22 \%)$ & $81(41 \%)$ & $<0.01$ \\
ALS & $331(71 \%)$ & $184(92 \%)$ & $<0.001$ \\
Alive to hospital & $38(8 \%)$ & $29(15 \%)$ & $<0.05$ \\
Survived 30 days & $9(2 \%)$ & $15(8 \%)$ & $<0.001$
\end{tabular}

ALS, advanced life support, nearly always supplied by ambulance personnel; CPR, cardiopulmonary resuscitation. 
those that included only cases in which resuscitation had been attempted or that included arrests not caused by coronary heart disease. ${ }^{8-11}$ A limitation of the study is that people aged 76 years or older, an increasing proportion of patients, were excluded. Contemporary data from UK hospitals as recorded by the Myocardial Infarction National Audit Project (MINAP) show that nearly one third of hospital patients with acute myocardial infarction and one quarter of survivors of arrest in hospital are now over 75 years old..$^{14}$ ) Similar figures for arrests occurring outside hospital in busy public places are provided by the UK government led programme for rapid access defibrillation. ${ }^{67}$ In nearly 700 events, about $25 \%$ of the arrest victims and $15 \%$ of the survivors were aged 76 or older ( $M$ Colquhoun, personal communication).

Extrapolation of our results to the total UK population, with the assumption that we recorded only $75 \%$ of arrests and $85 \%$ of survivors, suggests that there would be more than 9000 arrests in a public place each year, about 8000 of which would be witnessed. Assuming similar success rates, there would be about 640 survivors in the UK annually, but we previously calculated ${ }^{12}$ that there would be three times as many (1920) if success rates would be improved to match those in the most successful overseas centres ${ }^{89}$ or those in one UK centre during the 1980s. ${ }^{15}$ To what extent public access defibrillation will improve matters is controversial, ${ }^{6}{ }^{16}$ but other population based studies ${ }^{17}{ }^{18}$ agree with ours that it can be applicable only to about $20 \%$ of out of hospital arrests (although slightly more for younger victims) (table 1) and it depends on what proportion of arrests occur in places where a defibrillator is available. ${ }^{19}$ At the time of writing, nearly all of the 700 defibrillators that have been provided under the UK national defibrillator scheme are at main line railway stations and airports. ${ }^{7}$ The UKHAS catchment area included no airports and three main line stations, and we knew of only one arrest that occurred at a station restaurant. As fire and police stations are much more widely distributed than ambulance stations, it is perhaps arguable that further devolution of defibrillation skills to fire service personnel or police ${ }^{16}$ coupled with more intensive training of the public in basic life support, possibly starting in schools, ${ }^{20}$ may be of greater benefit than public access defibrillation for the wide variety of public places in which cardiac arrest can occur.

We believe that ours may be the first attempt to discover the presence or absence of premonitory symptoms before the arrest. We recorded premonitory symptoms in $72 \%$ of people who had a witnessed arrest at home and in whom the presence or absence of symptoms could be ascertained, and these appeared to have lasted for longer than 15 minutes in the majority. Although these people were older than those who had an arrest in a public place, they had no greater comorbidity, and many may have returned home after the onset of premonitory symptoms. Had they sought help earlier, they would have transferred from the group with a $2 \%$ survival rate (nine of 464 ) (table 2) to the group whose arrest was witnessed by a doctor or paramedic, 101 patients in all, of whom 35 (35\%) survived.

Public education campaigns to persuade the public to dial an emergency number in the event of new chest pain lasting 15 minutes or longer have had varying degrees of success but have shown on the whole that public behaviour, if not survival rates, can be modified. ${ }^{21}$ In a small study we showed a striking deficiency of public knowledge on the causes and treatment of heart attack, which was improved by distribution of booklets from doctors' surgeries. ${ }^{22}$ Most of the earlier public education was attempted over a relatively short period through the media and it seems that, apart from better primary and secondary prevention, a longer more intensive educational effort is the most promising way by which the mortality burden of arrests occurring in the home can be alleviated.

\section{ACKNOWLEDGEMENTS}

I am grateful to Professor Douglas Chamberlain for encouragement and advice in writing this paper.

The UKHAS was supported by audit funds from the Department of Health and by the PPP Medical Trust (RMN). We are grateful to the Coroners and Coroners' pathologists in the participating centres for allowing us access to their reports.

UKHAS Collaborative Group: R M Norris, P S Wong, G Dixon, N Morris, W J Penny, N El Gaylani, A Thomas, L Davies, R M Boyle, K Griffith, S Cooper (a full list of collaborators appears in the appendix)

\section{APPENDIX}

Participating centres: Brighton (coordinating centre, Cardiac Department, Royal Sussex County Hospital): R M Norris (honorary consultant cardiologist, study director), Gaynor Dixon (research sister responsible for coordination and database management), P S Wong (research registrar), and Nina Morris(research sister). Cardiff (Department of Cardiology, University Hospital of Wales): W J Penny (consultant cardiologist), Nadia El Gaylani (research registrar), Anne Thomas (research sister), and Lesley Davies (research sister). York (Department of Cardiology, York District Hospital): R M Boyle (consultant cardiologist), Kathryn Griffith (research registrar), Sian Wiseman (research sister), and Sue Cooper (research sister).

\section{REFERENCES}

1 Baum RS, Alvarez H, Cobb LA. Survival after resuscitation from out-of-hospital ventricular fibrillation. Circulation 1974;50:1231-5.

2 Tunstall-Pedoe H, Kuulasmaa K, Amouyel P, et al. Myocardial infarction and coronary deaths in the World Health Organization MONICA project: registration procedures, event rates and case-fatality rates in 38 populations from 21 countries in four continents. Circulation 1994;90:583-612.

3 Norris RM, on behalf of the United Kingdom Heart Attack Study Collaborative Group. Fatality outside hospital from acute coronary events in three British health districts 1994-95. BMJ 1998;316:1065-70.

4 Norris RM, on behalf of the Southern Heart Attack Response Project (SHARP). A new performance indicator for acute myocardial infarction. Heart 2001;85:395-401.

5 Thompson RG, Hallstrom AP, Cobb LA. Bystander-initiated cardio-pulmonary resuscitation in the management of ventricular fibrillation. Ann Intern Med 1979;90:737-40.

6 Davies CS, Colquhoun M, Graham S, et al. Defibrillators in public places: the introduction of a national scheme for public access defibrillation in England. Resuscitation 2002;52:13-21.

7 Department of Health. National defibrillator programme. 2005. www.dh.gov.uk/PolicyAndGuidance/HealthAndSocialCareTopics/ CoronaryHeartDisease/CoronaryPromotionProject/fs/en (accessed 13 June 2005).

8 Cobb LA, Weaver WD, Fahrenbruch CE, et al. Community-based interventions for sudden cardiac death: impact, limitations and changes. Circulation 1992;85(1 suppl):198-102.

9 Kuisma M, Maatha T. Out-of-hospital cardiac arrests in Helsinki: Utstein style reporting. Heart 1996;76:18-23.

10 Pell JP, Sirel JM, Marsden AK, et al. Effect of reducing ambulance response times on deaths from out-of-hospital cardiac arrest: cohort study. BMJ 2001;322:1385-8.

11 Herlitz J, Eek M, Engdahl J, et al. Factors at resuscitation and outcome among patients suffering from out of hospital cardiac arrest in relation to age. Resuscitation 2003;58:309-17

12 Norris RM, on behalf of the UK Heart Attack Study investigators. Sudden cardiac death and acute myocardial infarction in three British health districts: the UK heart attack study. London: British Heart Foundation, 1999.

13 Vincent R, Martin B, Williams G, et al. A community scheme in cardiopulmonary resuscitation. BMJ 1984;288:617-20.

14 Norris RM, Lowe D, Birkhead JS. Can successful treatment of cardiac arrest be a performance indicator for hospitals? Resuscitation 2004;60:263-9.

15 Lewis SJ, Holmberg S, Quinn E, et al. Out-of-hospital resuscitation in East Sussex 1981-89. Br Heart J 1993;70:568-73.

16 Pell JP, Sirel JM, Marsden AK, et al. Potential impact of public access defibrillators on survival after out of hospital cardiopulmonary arrest: retrospective cohort study. BMJ 2002;325:515-7.

17 De Vreede-Swagermakers JJ, Gorgels AP, Dubois-Arbouw WL, et al. Out-ofhospital cardiac arrest in the 1990s: a population-based study in the Maastricht area on incidence, characteristics and survival. J Am Coll Cardiol 1997; 30:1500-5.

18 Chugh SS, Jui J, Gunson K, et al. Current burden of sudden cardiac death: multiple source surveillance versus retrospective death certificate-based review in a large US community. J Am Coll Cardiol 2004;44:1268-75. 
19 Becker L, Eisenberg M, Fahrenbruch C et al. Public locations of cardiac arrest: implications for rapid access defibrillation. Circulation 1998;97:2106-9

20 Lester C, Donnelly P, Weston C, et al. Teaching school children in cardiopulmonary resuscitation. Resuscitation 1996;31:33-8.
21 Gaspoz JM Unger PF, Urban $\mathrm{P}$, et al. Impact of a public campaign on pre-hospital delay in patients reporting chest pain. Heart 1996;76:150-5.

22 Dixon GF, Norris RM, Vincent R. Heart attack action! A campaign to increase the community knowledge [abstract]. Heart 1996;75:80.

\section{IMAGES IN CARDIOLOGY}

\section{Coronary-cameral fistula}

A

57 year old male smoker, with a long history of hypertension, presented with angina. The physical examination was unremarkable. An ECG showed sinus rhythm and $\mathrm{T}$ inversion over lateral leads. A coronary angiogram (panel A) showed normal left anterior descending (LAD) and circumflex arteries. An extremely tortuous coronary fistula forming multiple loops was observed. The origin of the fistula from the LAD was not clearly seen from multiple views and it appeared to drain into the coronary sinus.

A contrast enhanced multislice spiral computer tomography (MSCT) with retrospective ECG gated reconstruction was performed to delineate the site of origin and termination of the fistula. Multiplanar reconstruction images showed the fistula originated from a diagonal branch of LAD and it formed multiple loops before terminating in the left ventricular cavity (panels B, C).

The patient underwent exercise thallium which was negative for myocardial ischaemia. In view of the stable angina, absence of heart murmur, and no objective evidence of coronary artery steal, the patient was managed conservatively.

Coronary-cameral fistulas are often caused by aberrancies of normal embryological development. Major sites of origin of fistula are the right coronary artery $(55 \%)$, left coronary artery $(35 \%)$, and both coronary arteries (5\%). Major termination sites are the right ventricle $(40 \%)$, right atrium

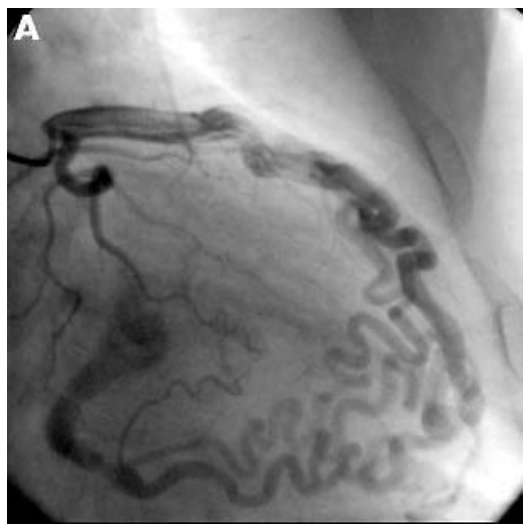

Selective angiography of the left main coronary artery from right anterior oblique view.

(26\%), pulmonary arteries (17\%), and less frequently the superior vena cava or coronary sinus, and least often the left atrium and left ventricle. The resultant physiologic derangement depends upon the site of origin and termination of the fistula and the size of the connection. The current case demonstrates that the size and anatomical features of a coronary-cameral fistula can be reliably established by MSCT, as opposed to conventional methods such as coronary angiography or with retrograde thoracic and aortic root aortography.

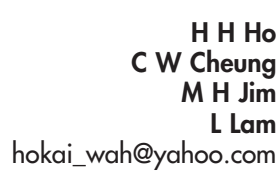

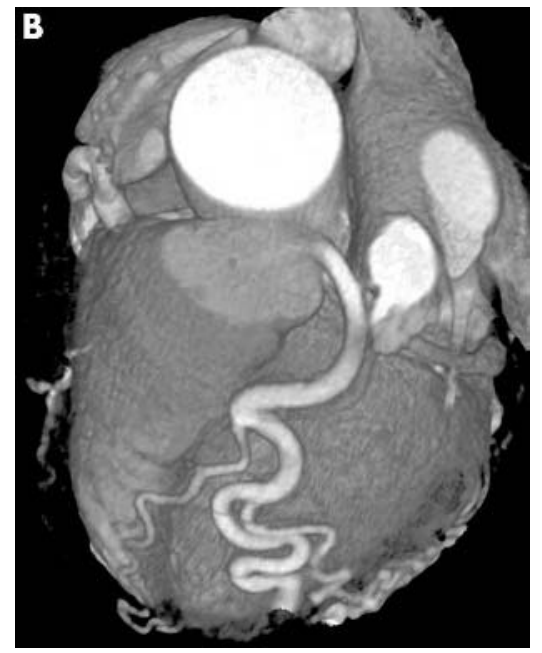

Three dimensional reconstruction image of multislice spiral computed tomography (MSCT) showing the origin of the coronary fistula from the dilated diagonal branch and the small left anterior descending coronary artery distal to the site of origin.

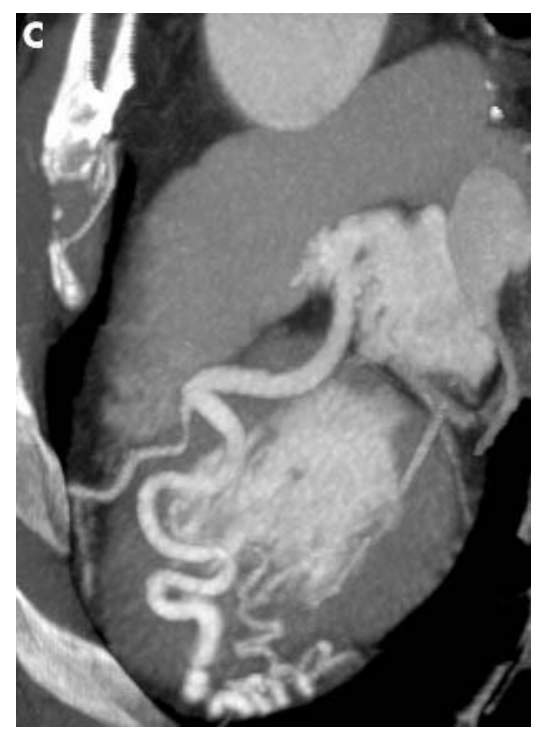

Sagittal view of MSCT showing coronary fistula terminating in the left ventricular cavity. 